\title{
Oral Medicine:
}

\section{The Awareness of Patients Using Steroid Inhalers on the Increased Risk of Oral Candidosis: A Service Evaluation}

\author{
*Saleh Nasser Aldallal ${ }^{1}$ and Christopher Hardy ${ }^{2}$ \\ ${ }^{1}$ Medical Student, University of Manchester, England \\ ${ }^{2}$ Consultant in Respiratory Medicine, Manchester Royal Infirmary
}

Received: October 06, 2017; Published: October 17, 2017

*Corresponding author: Mr. Saleh Nasser Aldallal BChD, MFDS RCS (Ed), MSc, The University of Manchester, Manchester, M13 9PL, USA, Email: S.n.aldallal@doctors.org.uk

Abstract

Objective: To perform an evaluation of the current practice of informing patients on steroid inhalers of the increased risk of oral candidosis (thrush) as a side effect of using the inhaler.

Method: This is a service evaluation in the form of a survey distributed to patients attending the respiratory medicine outpatient clinic at the Manchester Royal Infirmary (MRI).

Results: The evaluation shows that the majority of patients are not informed of the risk associated with commonly prescribed steroid inhalers, and they feel that it is the responsibility of the doctors to warn them about this side effect. Very few patients received advice from their dentist on this matter.

Conclusion: All healthcare professionals are responsible for the well-being of their patients. Dentist should play active role in advising patients on the oral side effects associated with the use of steroid inhalers.

\section{Clinical Relevance}

To perform an evaluation of the current practice of informing patients on steroid inhalers of the increased risk of oral candidosis as a side effect of using the inhaler.

\section{Introduction}

Asthma and Chronic Obstructive Pulmonary Disease (COPD) are common respiratory diseases affecting 5.4 and 3.2 million people of the UK population, respectively [1,2]. One of the treatments used for these conditions is steroid inhalers [3]. Steroid inhalers suppress the inflammatory reaction in the lung, which reduces the airway hyper responsiveness to allergens and irritants [3,4]. In 2014, 19.4 million steroid inhalers were dispensed in the community [5]. However, a prominent side effect of this intervention is the local suppression of the immune system, a phenomenon which could result in fungal infection [6-8].

A clinical trial comparing patients on steroid inhalers, nonsteroid inhalers and healthy subjects found that using steroid inhalers has a statistically significant effect on the count of oral Candida albican [9]. This was greater and dose-dependent in patients on fluticasone in contrast to those using beclomethasone $[9,10]$. However, a previous study found no correlation between the type of inhaler or the dose [7]. The risk increases with the concomitant use of broad-spectrum antibiotics, oral steroids and in diabetics [10]. A high C.albicans count increases the risk of oral candidosis, and once candidosis is established, antifungal treatment should be commenced.

The incidence of oral candidosis in patients on steroid inhalers could be as high as $61 \%$ with clinical symptoms and $66 \%$ with subclinical candidosis [11]. Unfortunately, most of those studies were of inferior design with short follow-up time and lack of control group. Few measures have been proposed to lower the incidence of steroid inhaler-induced oral candidosis. These include: the use of spacer [12], dose reduction $[13,14]$ and the use of amphotericin B mouth rinse [9]. However, simple measures such as a mouth rinse with water after using steroid inhalers have a significant effect on reducing oral candida counts in patients on steroid inhalers [13-15]. As healthcare professionals, it is our duty to ensure the well-being of our patients. This includes the prevention and management of potential side effects induced by the treatment we provide. 
Therefore, advising patients on steroid inhalers to rinse after using the inhaler and emphasising the importance of regular visits to the dentist should be an integral part of our treatment plan for such patients. Between 2011 and 2013, the British Lung Foundation (BLF) produced a leaflet titled "Steroids and your lungs". It included information about the risk of oral candidosis and voice hoarseness as side effects of using steroid inhalers. It advised patients to use a spacer, mouth rinsing after use, oral antifungals and drinking fresh pineapple juice as measures to prevent such a complication [16]. Unfortunately, this leaflet was only circulated for a brief period of time before being discontinued. The BLF explained that they review their leaflets regularly, and that due to limited resources, some of the leaflets had to be discontinued. Fortunately, reliable websites have the same information and they are still accessible to everybody $[17,18]$.

However, not all patients access those webpages to read about the condition and its prevention and management strategies. This is a service evaluation aiming to explore the awareness of patients of steroid inhalers and the increased risk or oral candidosis (thrush) as a side effect of using the inhaler. To the best of the authors' knowledge, no previous evaluations explored this area from the patients' point of view.

\section{Materials and Methods}

The student attended outpatient clinics at the department of respiratory medicine during the project period (January, 2016 to February, 2016). All attending patients were given the invitation letter and offered to participate in the questionnaire. Those patients who agreed to participate were given the questionnaire to complete anonymously and then drop it in the box. To avoid multiple entries from patients attending a follow-up appointment, they were asked if they had participated in the study. If they had or could not remember, they were not included in the evaluation. Statistical analysis was performed using IBM SPSS Statistics (Version 20.0; IBM Corp., Armonk, NY, USA). "Free text" comments from participants were reviewed by the researcher without statistical analysis. Descriptive statistics such as frequency and \% were used for the nominal/ordinal data and the mean and standard deviation for the interval/ratio data. As this is a service evaluation, a hypothesis testing was not carried out.

\section{Results}

During a period of four weeks, the student attended six outpatient clinics. A total of 234 patients attended those clinics (average of 39 patients per session) both as new referrals or followups. Every patient was offered the questionnaire to complete and there were 203 returned questionnaires (86.7\% return rate) and all of them were completed correctly and included in the analysis. Out of the 203 patients, 148 patients (72.91\%) used inhalers as part of their treatment. Only patients who were using steroid-based inhalers $(n=142)$ were included in the analysis of warning of side effects of using such inhalers. Most of these patients, amounting to $57.4 \%(n=82)$, were not warned about possible side effects of steroid inhalers, while $6 \%(n=8)$ were not sure or cannot remember if they have been warned (Figure 1).

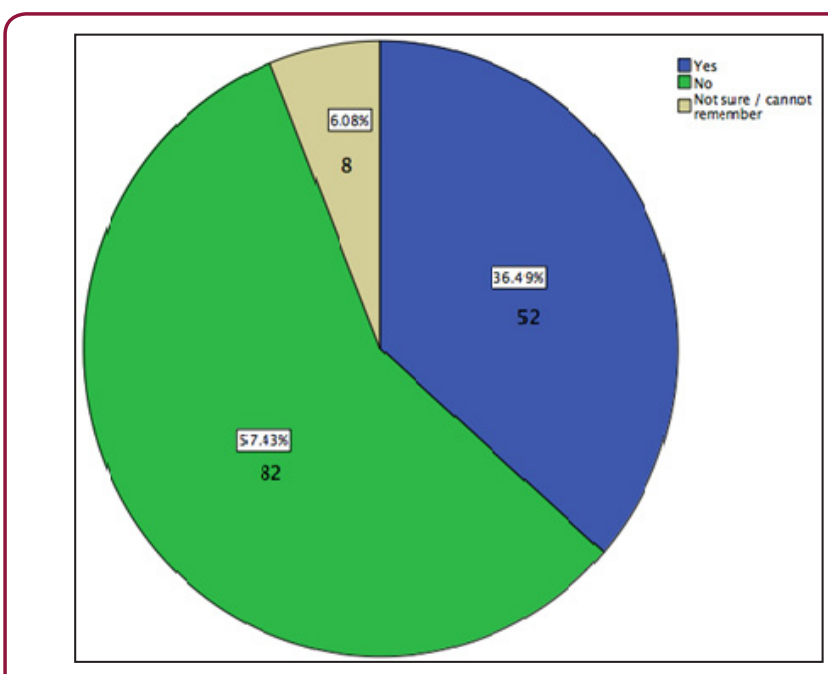

Figure 1: Have you been warned about possible mouth problem effects as a result of using your inhaler?

Table 1: What side effect were you warned about?

\begin{tabular}{|c|c|c|}
\hline $\begin{array}{c}\text { What side effect you were } \\
\text { warned about }\end{array}$ & Frequency & Percentage \\
\hline Mouth fungal infection & 39 & $75 \%$ \\
\hline Hoarse voice & 8 & $15.3 \%$ \\
\hline Tooth decay & 6 & $11.5 \%$ \\
\hline Gum disease & 2 & $3.8 \%$ \\
\hline Other & 0 & 0 \\
\hline
\end{tabular}

Table 2 : Advice given to patients to avoid oral candidosis as a result of using steroid inhalers.

\begin{tabular}{|c|c|c|}
\hline Advice given & Frequency & Percentage \\
\hline No advice given & 20 & $38.4 \%$ \\
\hline $\begin{array}{c}\text { Use a Spacer } \\
\text { Brush your teeth after } \\
\text { use }\end{array}$ & 20 & $3.6 \%$ \\
\hline $\begin{array}{c}\text { Rinse with water after } \\
\text { use }\end{array}$ & 32 & $61.5 \%$ \\
\hline $\begin{array}{c}\text { Rinse with antiseptic } \\
\text { mouthwash }\end{array}$ & 0 & $11.5 \%$ \\
\hline $\begin{array}{c}\text { Use anti fungal } \\
\text { medication }\end{array}$ & 2 & $3.8 \%$ \\
\hline Regular dental visits & 0 & 0 \\
\hline Other & 6 & 0 \\
\hline
\end{tabular}

The warnings received by the remaining $36.49 .6 \%(n=52)$ are summarised in Table 1 . Some patients were warned about more than one side effect associated with steroid inhalers. Therefore, the total number of frequencies exceeds that of patients being warned, and the sum percentages exceeds $100 \%$. Some of the patients who were warned about possible side effects of using steroid inhalers did not receive any advice to avoid this side effect, while other patients received different forms of advice. The advice given to patients to 
avoid oral candidosis is summarised in Table 2. All patients who mentioned that they were advised to use antifungal medication had at least one episode of oral candidosis, which might suggest that they were warned about this side effect after they had the infection.

As patients could have received more than one form of advice, the total number of frequencies exceeds that of patients being advised and the sum percentage exceeds $100 \%$. All of the patients thought that it is the responsibility doctors to warn them about the side effects of the drugs they prescribe. However, some thought that it is the pharmacist's and possibly dentist's responsibility in addition to the prescriber's. Notably, this evaluation shows that only $55.7 \%(n=29)$ of the patients, who were warned about the side effects of their inhalers were advised by their doctor regarding the side effects of steroid inhalers.

All patients who chose "other" (28 \%, $\mathrm{n}=16)$ as a response to the question (who warned you about the side effects?) specified that it was the specialist nurse who warned them. Table 3 shows that some of the patients were treated for oral candidosis since they started using the inhalers (average of two episodes per patient) and the majority of them were not warned about this side effect beforehand and as explained earlier,some of those patients might have been warned about this side effect after they had the infection. No association was found between the condition patients were treated for and suffering from an oral candidosis episode.

Table 3: A comparison between patients who suffered from oral candidosis since they started using steroi inhalers in terms of warnings they received about the side effect of the inhalers.

\begin{tabular}{|c|c|c|c|c|}
\hline & & \multicolumn{2}{|c|}{$\begin{array}{l}\text { Since you started using your inhaler, have you } \\
\text { been treated for mouth fungal infections? }\end{array}$} & \multirow{2}{*}{ Total } \\
\hline & & Yes & No & \\
\hline \multirow[t]{6}{*}{$\begin{array}{l}\text { Have you been warned } \\
\text { about possible mouth } \\
\text { problems as a side } \\
\text { effect of using your } \\
\text { inhaler? }\end{array}$} & Yes & 16 & 34 & 50 \\
\hline & & $39.0 \%$ & $33.6 \%$ & \\
\hline & No & 24 & 60 & 84 \\
\hline & & $58.5 \%$ & $59.4 \%$ & \\
\hline & $\begin{array}{l}\text { Not sure } / / \text { cannot } \\
\text { remember }\end{array}$ & 1 & 7 & 8 \\
\hline & & $2.4 \%$ & $7.0 \%$ & \\
\hline \multicolumn{2}{|c|}{ Total } & 41 & 101 & 142 \\
\hline
\end{tabular}

\section{Discussion}

This evaluation shows that there is a deficit in the doctors'approach to advise patients on the side effects of steroid inhalers they prescribe. It also illustrates the important role played by other healthcare professionals (e.g. pharmacists and nurses) in warning patients about the side effects of the drug they are using. Those patients who had an episode of oral candidosis and indicated that they had been warned may have been only been warned after contracting an infection. This is because some of those patients indicated that they were advised to use antifungal medication to avoid this side effect. The other interesting finding is the fact that the spacer was rarely advised to patients on steroid inhalers as a measure to reduce the risk of oral candidosis.

Some patients mentioned that they were warned about tooth decay and gum disease as a side effect of using their inhaler. In terms of gum disease, patients could be referring to oral candidosis and they are confusing mucosa and gum. With regards to dental caries, no association between steroid inhalers and caries has been mentioned in the literature and it is not clear why those patients were warned about this side effect. Again, it could be that those patients were warned about oral side effects and they forgot what those side effects are. A few patients were advised by their dentist regarding the oral side effects of the inhalers they use. This could be due to the fact that some patients are not registered with a dentist or do not see their dentist regularly.

On reflection, this evaluation could be improved by conducting a multi-centre evaluation involving both primary and secondary care settings. Furthermore, due to different number of inhalers available, it was difficult to list them all in the questionnaire. Therefore, patients might not recognise the inhaler they use. It might be more appropriate to include a picture of the inhaler in the questionnaire. Some of the patients ticked "other" as the type of inhaler they use. However, they did not specify which inhaler they were using, and were therefore not considered as users of steroid inhalers. This could have skewed the data, as some of those patients were not warned about oral side effects of the inhalers, which could have been steroid-based.

\section{Conclusion}

In conclusion, advising patients on the side effects of prescribed drugs should be the responsibility of the prescriber as patients perceive it. However, it should also be the responsibility of all healthcare professionals to ensure the well-being of all their patients and not assume that advice has already been given by prescribers, therein ruling out any further role for them to play. This evaluation shows that only small proportion of patients has 
received advice on oral side effects of steroid inhalers from their dentists.

\section{Acknowledgment}

We are grateful to Miss Jackie Sheppard, specialist asthma nurse, for her assistance in the design of the questionnaire. We also appreciate the co-operation of Miss Sarah Leo, divisional research manager, for her help in obtaining the required approval to carry out this evaluation.

\section{Conflict of Interest}

Authors declare no conflict of interest.

\section{Ethical Implications}

The project was approved by the Research and Innovation division at the MRI. No ethical approval was required.

\section{References}

1. (2015) Asthma UK. Asthma facts FAQs.

2. (2010) Department of Health. Facts about COPD.

3. Kumar P, ML Clark, Kumar (2012) Clark's Clinical Medicine, ed. $8^{\text {th }}$ Elsevier Health Sciences UK.

4. (2015) Royal Pharmaceutical Society of Great, B, British National Formulary 69.

5. (2015) Prescribing and Medicines Team, Prescriptions Dispensed in the Community England 2004-2014. Health and Social Care Information Centre.

6. Dubus, JC, Marguet C, Deschildre A, Mely L, Le Roux P et al. (2001) Local side-effects of inhaled corticosteroids in asthmatic children: influence of drug, dose, age, and device. Allergy 56(10): 944-948.
7. Shaw NJ, AT Edmunds (1986) Inhaled beclomethasone and oral candidiasis. Archives of Disease in Childhood 61(8): 788-790.

8. Fukushima C, Matsuse H, Saeki S, Kawano T, Machida I et al. (2005) Salivary $\operatorname{IgA}$ and oral candidiasis in asthmatic patients treated with inhaled corticosteroid. Journal of Asthma,. 42(7): 601-604.

9. Fukushima C, Matsuse H, Tomari S, Obase Y, Miyazaki Y et al. (2003) Oral candidiasis associated with inhaled corticosteroid use: comparison of fluticasone and beclomethasone. Annals of Allergy, Asthma \& Immunology 90(6): 646-651.

10. Kennedy WA, Laurier C, Gautrin D, Ghezzo H, Paré M et al. (2000) Occurrence and risk factors of oral candidiasis treated with oral antifungals in seniors using inhaled steroids. Journal of Clinical Epidemiology 53(7): 696-701.

11. Ellepola AN, LP Samaranayake (2001) Inhalational and topical steroids, and oral candidosis: a mini review. Oral Diseases 7(4): 211-216.

12. Toogood JH, Frederick A White, Jon C, Baskerville, Lawrence J Fraher, et al. (1997) Comparison of the antiasthmatic, oropharyngeal, and systemic glucocorticoid effects of budesonide administered through a pressurized aerosol plus spacer or the Turbuhaler dry powder inhaler. Journal of Allergy and Clinical Immunology 99(2): 186-193.

13. Lipworth, BJ (1993) Clinical pharmacology of corticosteroids in bronchial asthma. Pharmacology and Therapeutics 58(2): 173-209.

14. Jackson LD (1999) Comparative efficacy and safety of inhaled corticosteroids in asthma. The Canadian Journal of Clinical Pharmacology 6(1): 26-37.

15. Dempsey OJ, Coutie WJ, Wilson AM, Williams P, Lipworth BJ (1999) Evaluation of the buccal component of systemic absorption with inhaled fluticasone propionate. Thorax 54(7): 614-617.

16. British Lung Foundation, Steroids and your lungs. 2011: London.

17. (2015) Asthma UK. Preventer inhalers.

18. (2015) NHS. Preventer inhalers. Asthma.

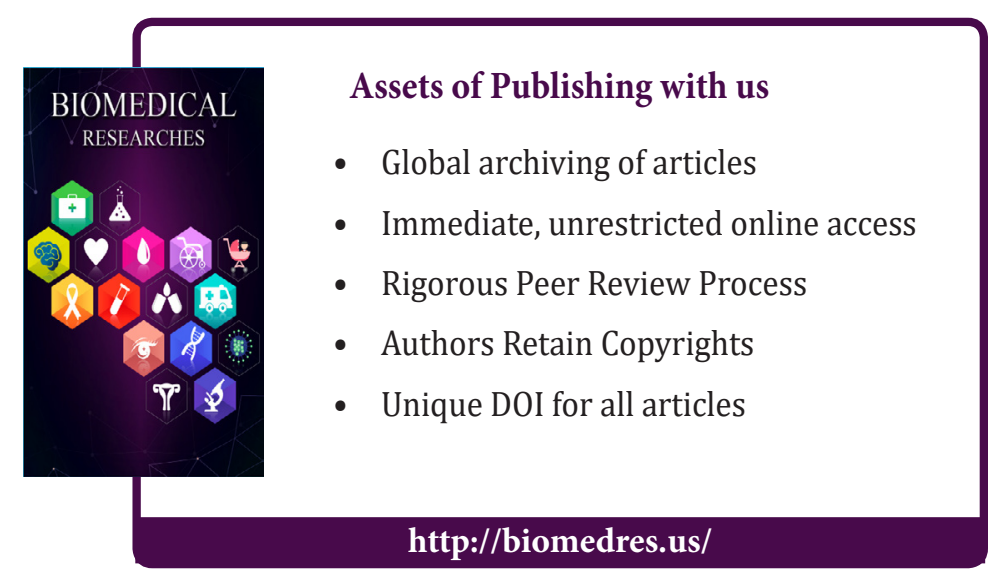

